Research Article

\title{
Evolution Characteristics of the Cracks in the Completely Disintegrated Carbonaceous Mudstone Subjected to Cyclic Wetting and Drying
}

\author{
Ling Zeng, ${ }^{1}$ Jie Liu $\left(\mathbb{D},{ }^{2}\right.$ Qian-Feng Gao $\mathbb{D}^{\circ},{ }^{2}$ and Hanbing Bian ${ }^{1}$ \\ ${ }^{1}$ School of Civil Engineering, Changsha University of Science \& Technology, Changsha 410114, China \\ ${ }^{2}$ School of Traffic \& Transportation Engineering, Changsha University of Science \& Technology, Changsha 410114, China \\ Correspondence should be addressed to Qian-Feng Gao; qianfeng.gao8@gmail.com
}

Received 18 February 2019; Revised 28 April 2019; Accepted 13 May 2019; Published 28 May 2019

Academic Editor: Timo Saksala

Copyright (c) 2019 Ling Zeng et al. This is an open access article distributed under the Creative Commons Attribution License, which permits unrestricted use, distribution, and reproduction in any medium, provided the original work is properly cited.

Completely disintegrated carbonaceous mudstone, a common embankment material, has significant swelling-shrinkage behavior under cyclic wetting and drying, which often causes the instability of embankments. In this paper, the evolution of the cracks in the completely disintegrated carbonaceous mudstone subjected to cyclic wetting and drying was studied by laboratory tests. The vacuum saturation method and the drying method based on heat lamps and a fan were employed to simulate the wetting and drying processes, respectively. The image processing technique was used to treat the images of the sample surface. Afterward, various geometric parameters of the cracks appeared on the sample surface were measured, and the evolution characteristics of the cracks were analyzed. The results show that with the increase in the number of wetting and drying cycles, the number of cracks on the sample surface gradually increases. After four wetting and drying cycles, the existing cracks produce a large number of small branches, which are connected to form irregular polygonal grids. The development of the cracks in the completely disintegrated carbonaceous mudstone sample can be divided into three stages, i.e., slow development, rapid development, and stable development. Both the surface density of crack and the crack rate first increase and then tend to be stable with the increasing number of wetting and drying cycles. New cracks are mainly generated on the basis of the existing cracks, and some cracks appear to heal under cyclic wetting and drying. The early cracks are mainly developed in the directions of $0^{\circ}-90^{\circ}$ and $300^{\circ}-360^{\circ}$, and the development rate of the cracks in the directions of $30^{\circ}, 90^{\circ}, 140^{\circ}-150^{\circ}$, and $180^{\circ}-270^{\circ}$ is significantly higher than that of the cracks in other directions.

\section{Introduction}

Carbonaceous mudstone, which is widely distributed in southwestern China, is easy to disintegrate after seasonal rainfall. To protect the environment and reduce the cost, the completely disintegrated carbonaceous mudstone has frequently been used as fillings in embankment engineering [1-3]. However, the completely disintegrated carbonaceous mudstone has significant swelling, shrinkage, and cracking characteristics because it contains a high content of hydrophilic minerals. When subjected to cyclic wetting and drying, massive crisscross networks of crack are often developed in this material or on its surface $[4,5]$. The generation of cracks can destroy the original structure of the soil and greatly weaken the bearing capacity of the embankments made of completely disintegrated carbonaceous mudstone [6]. Furthermore, the existence of cracks provides convenient channels for water to infiltrate into the soil, which accelerates the instability of the embankment slope and finally induces engineering disasters [7]. Therefore, the development of cracks is a major hazard to the stability of the embankments constructed with completely disintegrated carbonaceous mudstone.

Over the past two decades, a global climate change has led to the frequent occurrence of extreme rainfall and arid climate $[8,9]$. The cracking problem of soil and rock subjected to cyclic wetting and drying has been the interest of many scholars and engineers [10-15]. The laboratory test is 
commonly used to examine the evolution characteristics of cracks in soil. Previous experimental studies have revealed that the sample geometry has a great influence on the crack characteristics. The crack pattern, particularly that near the boundary, is more or less affected by the sample shape because the cracks at the boundary are usually perpendicular to the boundary surface [16]. As the thickness of soil sample increases, the number of cracks decreases while the primary cracks become wider; as the sample size increases, the numbers of cracks per unit area and isolated soil blocks increase, and the primary cracks become wider [17, 18]. Nevertheless, some researchers demonstrated that laboratory tests often give different results from those obtained in the field although the differences may not be very significant $[19,20]$. Indeed, this discrepancy is expected because the field soils are much more heterogeneous and are conditioned by various environmental factors such as the variable climatic conditions and the presence of surface vegetation cover, which are often effaced in the laboratory tests [15]. Compared with the field observation, the laboratory test allows precisely controlling both the internal and external variables, which not only greatly improves the reproducibility of test results but also helps reveal the intrinsic behavior of soil. This is why the laboratory test is more popular with researchers for investigating the evolution of drying cracks.

Furthermore, the quantitative analysis has been a hot mean to study the influence of cracks on the soil properties under cyclic wetting and drying. The shape parameters (e.g., width, length, spacing, and depth) of crack that are closely related to the engineering properties of soil are used as important indicators to characterize the degree of cracks development $[16,17,20,21]$. The methods for crack measurement are also increasingly diverse. For instance, the photography, computed tomography (CT), ultrasonic testing (UT), and conductance method (CM) have widely been applied to observe the soil structure including cracks in the literature [22-25]. However, there are very few instruments that allow the continuous, nondestructive observation of the development of cracks during wetting and drying tests. Moreover, the previous researches of crack characteristics were mainly focused on clay and expansive soils, and little relevant work was conducted on the completely disintegrated carbonaceous mudstone.

The above analyses indicate that it is of great significance to study the evolution characteristics of the cracks in the completely disintegrated carbonaceous mudstone subjected to cyclic wetting and drying. For this reason, an instrument for crack evolution tests was developed in this study. The wetting and drying tests were then carried out on the completely disintegrated carbonaceous mudstone under cyclic wetting and drying. Afterward, the image processing technique based on the Image Pro-Plus (IPP) software and the MATLAB program was used to analyze the images of the sample surface. In addition, the variation in the direction of crack development was characterized by a rose diagram. Finally, the evolution mechanism of the cracks in the completely disintegrated carbonaceous mudstone subjected to cyclic wetting and drying was discussed.

\section{Materials and Experiment Method}

2.1. Materials and Sample Preparation. Carbonaceous mudstone is widely distributed in southwestern China. Typical completely disintegrated carbonaceous mudstone was collected from the site of $\mathrm{K} 18+500$ of the Liuzhai-Hechi expressway in Guangxi, China (Figure 1). The X-ray diffraction analysis showed that the mineral composition of the completely disintegrated carbonaceous mudstone is mainly calcite, quartz, chlorite, mica, and kaolinite; the mass fraction of the remaining mineral components is less than $10 \%$ (Figure 2). The raw material was sieved, and the grains smaller than $0.5 \mathrm{~mm}$ were used to prepare the test samples. The physical properties of the material were tested, and the main results are shown in Table 1 . According to the international soil classification standard [26], the material can be classified as low-plasticity silt with fine sand (ML).

To simulate the working condition of the embankment, the test samples were prepared at a degree of compaction of $96 \%$ and an initial water content of $14 \%$. First, the grains were fully mixed with distilled water, sealed with a film bag, and then placed in a moisturizer box for $48 \mathrm{~h}$. Afterward, the grains were weighed and then poured into the direct shear ring cutters with inner diameters of $61.8 \mathrm{~mm}$ and heights of $20 \mathrm{~mm}$ as used by Sun et al. [27] and Zhang et al. [28] among others. The bottoms of the direct shear ring cutters were sealed with filter papers placed on a test platform and the inner walls were coated with thin layers of Vaseline to simulate the in situ boundary condition. According to the work of Zhang et al. [29], this treatment of the sample containers would characterize the field boundary condition well because the drying shrinkage is mainly constrained by the underlying soil mass. The grains were then statically compacted by a jack, and thus the circular plate samples were produced. Finally, the samples were sealed with fresh film after sample formation and then stored in a humiditycontrolled box at a relative humidity of $100 \%$.

2.2. Test Instrument. A new test instrument was developed to investigate the evolution of the cracks in the completely disintegrated carbonaceous mudstone subjected to cyclic wetting and drying. As shown in Figure 3, the instrument consisted of a wetting system, a drying system, and a measurement system. The sample was soaked and saturated by the wetting system that mainly included a vacuum saturation cylinder and a saturator. The drying system that contained two heat lamps and a fan was used to dry the sample. The measurement system used a digital camera to capture the images of the sample surface in real time. The focal length of the digital camera was fixed all the time to avoid the problem of focal length and light inconsistency in different wetting and drying cycles.

2.3. Test Scheme. In order to reveal the evolution characteristics of the cracks in the completely disintegrated carbonaceous mudstone under cyclic wetting and drying, a series of tests was carried out. At the beginning of the tests, 


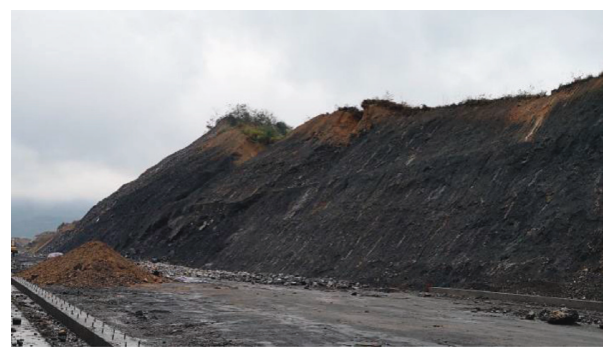

Figure 1: Carbonaceous mudstone at the embankment site.

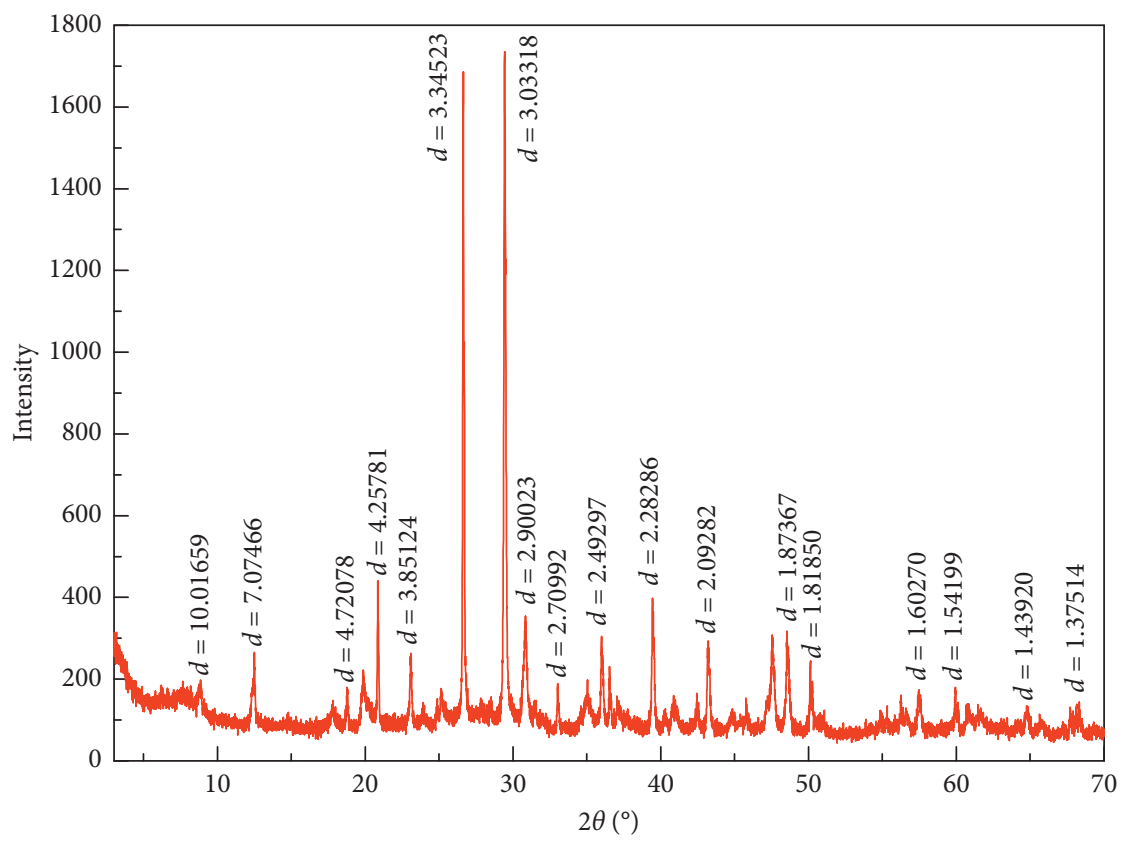

FIGURE 2: X-ray diffraction patterns of the completely disintegrated carbonaceous mudstone.

TABLE 1: Physical properties of carbonaceous mudstone after full disintegration.

\begin{tabular}{|c|c|c|c|c|c|c|}
\hline $\begin{array}{l}\text { Maximum dry density } \\
\left(\mathrm{g} / \mathrm{cm}^{3}\right)\end{array}$ & $\begin{array}{l}\text { Optimum water } \\
\text { content }(\%)\end{array}$ & Shrinkage limit (\%) & Liquid limit (\%) & Plastic limit (\%) & Plasticity index & Specific gravity \\
\hline 2.08 & 10.56 & 21.95 & 31.30 & 25.30 & 6.00 & 2.37 \\
\hline
\end{tabular}

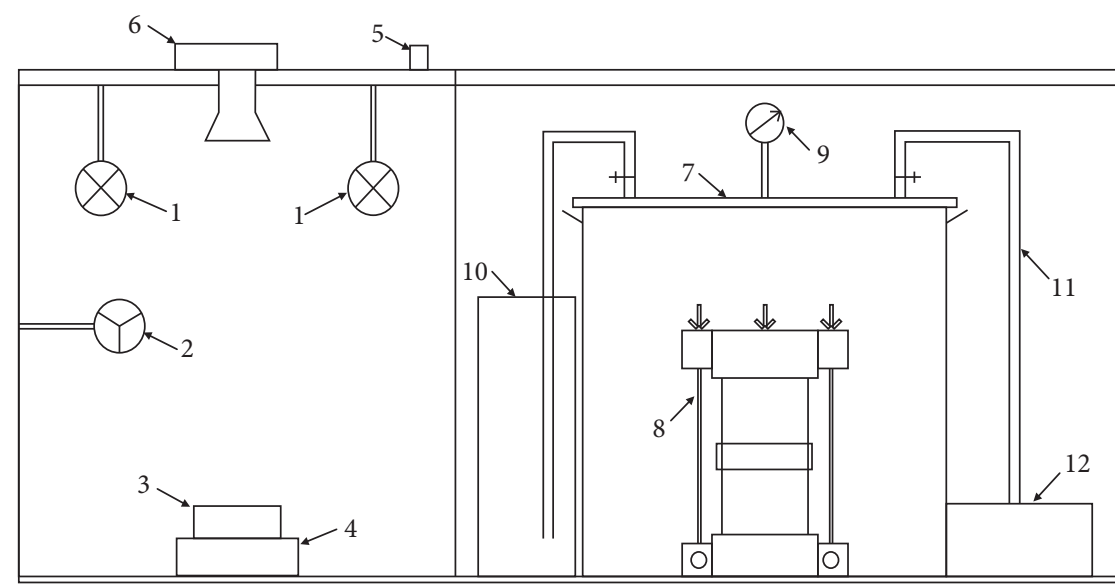

FIGURE 3: Sketch of the new test instrument. 1: heat lamp for drying the sample; 2: fan for accelerating the air convection; 3: sample; 4: electronic scale for weighing the sample; 5: exhaust vent for discharging the water vapor during drying; 6: digital camera for taking highdefinition images; 7: vacuum saturation cylinder for saturating the sample; 8: saturator for containing the sample; 9: piezometer for monitoring the pressure in the vacuum saturation cylinder; 10: bucket; 11: water pipe; 12: pump for providing vacuum power. 
the following three schemes had been used to achieve the goal:

(i) The sample was made of the completely disintegrated carbonaceous mudstone with particle sizes of less than $0.5 \mathrm{~mm}$. The cyclic wetting and drying environment was achieved by means of purling and natural air drying.

(ii) The sample was made of the completely disintegrated carbonaceous mudstone with particle sizes of less than $2 \mathrm{~mm}$. The self-developed test instrument was used to simulate the cyclic wetting and drying environment.

(iii) The sample was made of the completely disintegrated carbonaceous mudstone with particle sizes of less than $0.5 \mathrm{~mm}$. The self-developed test instrument was used to simulate the cyclic wetting and drying environment.

The results indicated that in scheme (i), the use of the purling method led disturbance to the existing cracks in the sample; in scheme (ii), because the particle size of carbonaceous mudstone was large while the average width of cracks was very small, the crack development was difficult to identify. Since scheme (iii) did not have the above problems, it was selected to test the completely disintegrated carbonaceous mudstone sample subjected to eight cyclic wetting and drying. To reduce the test error, three parallel tests were performed, and the experimental results were averaged. The test steps are as follows:

(1) The sample was transferred from the moisturizer box to the saturator. Then the saturator that contained the sample was put into the vacuum saturation cylinder.

(2) The water intake valve was closed, the suction valve was opened, and the pump was powered on to evacuate the wetting system. After 30 -min vacuum, the water intake valve was opened to let the water enter the vacuum saturation cylinder. The water intake valve and suction valve were both closed when the water fully covered the saturator. The sample was soaked in the vacuum saturation cylinder for $24 \mathrm{~h}$.

(3) The sample soaked for $24 \mathrm{~h}$ was placed on the electronic scale. The heat lamps and the fan were used to dry the sample. In the process of drying, the water content of the sample was tested every $5 \mathrm{~h}$. When the difference between the current water content and the initial water content was less than $5 \%$, the water content was tested every hour. Once the difference between two water contents measured in $2 \mathrm{~h}$ was less than $0.5 \%$, the process from wet to dry was considered complete.

(4) A proper focal length of the camera was selected and fixed, and then the camera was started to take photos of the sample surface.

(5) The wetting and drying cycles were repeated eight times to observe the evolution characteristics of the cracks in the completely disintegrated carbonaceous mudstone.

\section{Quantitative Methods for Identifying Crack Parameters}

3.1. Image Processing Method. IPP is an image analysis software platform with powerful functions of image processing, measurement, counting, data statistics, and analysis. According to the study in the literature [30], the image processing procedure included the following steps:

(1) The original image (Figure 4(a)) was imported into the IPP software and then converted to grayscale image (Figure 4(b)).

(2) The area of interest (AOI) was selected, and the binarization process in the processing command was used to segment the image. The binarized image is shown in Figure 4(c).

(3) The binarized image was imported into the MATLAB software. The "bwlabel" function available in the toolbox was used to identify the spots in the binarized image. Subsequently, the toolbox function of "regionprops" was employed to calculate the area of the spots, and then the area distribution curve of each spot was obtained. The optimal area threshold was obtained according to the area distribution curves. The spot-removed image, in which the black area represents the cracks and the white area represents the soil matrix, is shown in Figure 4(d).

(4) The image without spots was then imported into IPP again, and thus the geometric parameters of the cracks were calculated using an automatic counting command.

3.2. Quantitative Analysis of Crack Parameters. The morphology of cracks can be characterized by many parameters such as the crack number, maximum length, maximum width, surface density, and crack rate.

(1) Crack number $(N)$ is the total number of cracks. Since IPP distinguishes different objects by pixels, the uninterrupted line in the image is defined as a single crack while the interrupted lines are considered as different cracks (Figure 5).

(2) Maximum length $\left(l_{\max }\right)$ refers to the maximum value of the curve distances of all cracks along their lengthwise directions.

(3) Maximum width $\left(d_{\max }\right)$ refers to the maximum value of the linear distances of all cracks along their width directions; it reflects the degree of crack opening.

(4) Surface density $\left(\rho_{\mathrm{s}}\right)$ is defined as the ratio of the cumulative length of all cracks to the surface area of the sample, namely [16],

$$
\rho_{\mathrm{s}}=\frac{l_{\mathrm{t}}}{S_{\mathrm{B}}}=\frac{\sum_{i=1}^{N} l_{i}}{S_{\mathrm{B}}}
$$

where $\rho_{\mathrm{s}}$ is the surface density of cracks, $l_{\mathrm{t}}$ is the cumulative length of all cracks, $S_{\mathrm{B}}$ is the surface area 


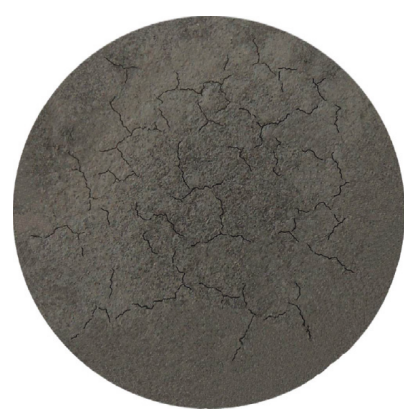

(a)

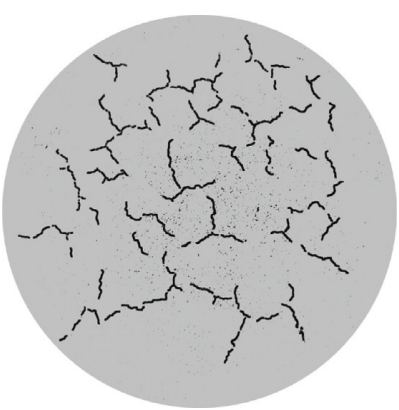

(b)

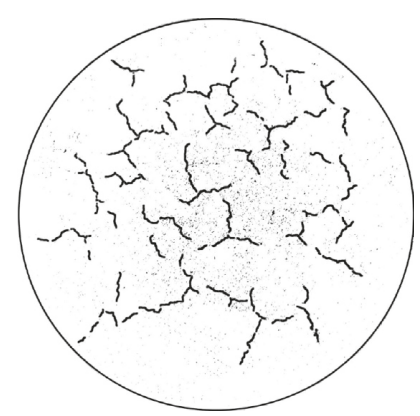

(c)

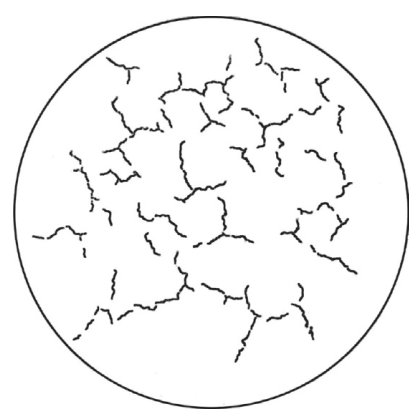

(d)

FIGURE 4: Main steps for processing the image that contained cracks. (a) Original image. (b) Grayscale image. (c) Binarized image. (d) Spotremoved image.

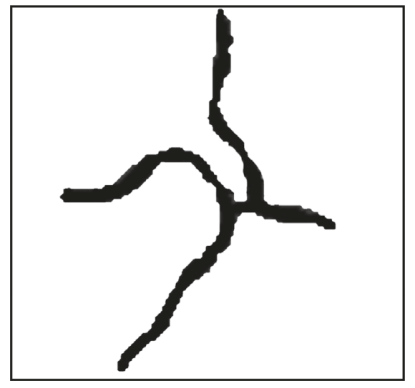

(a)

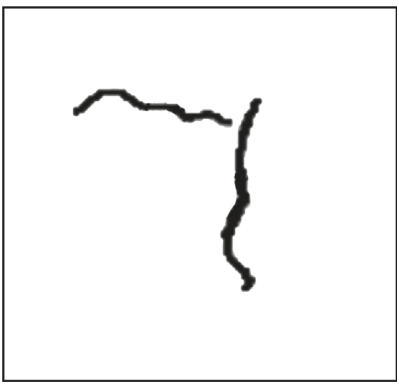

(b)

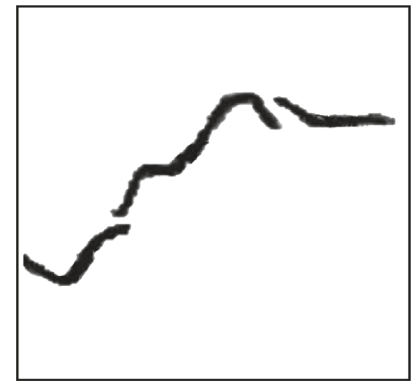

(c)

Figure 5: Determination of the crack number. (a) One crack. (b) Two cracks. (c) Three cracks.

of the sample, and $l_{i}$ is the cumulative length of the $i$ th crack.

(5) Crack rate $\left(\delta_{\mathrm{f}}\right)$ is defined as the ratio of the total area of cracks to the surface area of the sample; it reflects the degree of the development of the crack network. The crack rate is expressed by [16]

$$
\delta_{\mathrm{f}}=\sum_{i=1}^{N} \frac{A_{i}}{S_{\mathrm{B}}}=\frac{n_{\mathrm{b}}}{n_{\mathrm{b}}+n_{\mathrm{w}}}=\frac{n_{\mathrm{b}}}{n},
$$

where $\delta_{\mathrm{f}}$ is the crack rate; $A_{i}$ is the area of the $i$ th crack; $n_{\mathrm{b}}$ is the number of black pixels, and $n_{\mathrm{w}}$ is the number of white pixels; and $n$ is the total number of pixels.

(6) Total crack area $(A)$ is the sum of the areas of all cracks. Note that the total crack area does not equal to the sum of the products of the length and width of crack.

\section{Results and Discussion}

4.1. Evolution Phenomena of Macroscopic and Microscopic Cracks. The grayscale images of the cracks on the sample surface after different wetting and drying cycles are presented in Figure 6. It is noted that a few Y-shaped cracks appear on the surface of the completely disintegrated carbonaceous mudstone sample after one wetting and drying cycle. The number of cracks on the sample surface gradually increases as the number of wetting and drying cycles increase. After the fourth wetting and drying cycle, the primary and secondary cracks on the sample surface are interlaced, and the cracks are gradually connected to form irregular polygonal grids. With the increasing number of wetting and drying cycles, the cracks further expand, the number of polygon grids (i.e., soil blocks) divided by the cracks increases, and the average area of the grids decreases.

The appearance of the above phenomenon is mainly because the completely disintegrated carbonaceous mudstone has the characteristics of water swelling and drying shrinkage. The sample rests on a frictional support (i.e., filter paper base) and is fully saturated after vacuum saturation. In the process of drying, the rates of water evaporation on the top and bottom surfaces of the sample are different. In this case, the water content gradient is formed inside the sample and does not disappear in a short time. Therefore, the matric suctions on the sample surface and inside the sample are different, leading to the generation of surface cracks under constrained boundary conditions.

One can also note that some previously existed cracks are healed and a few healed cracks do not open again in the subsequent wetting and drying cycles. However, most of the cracks generated in a subsequent wetting and drying cycle follow the pattern of the cracks formed in the previous wetting and drying cycle, indicating good repeatability of the cracks to some extent. These results are acceptably consistent with those reported by $\mathrm{Li}$ and Zhang [20] and Yesiller et al. [31]. Moreover, compared with the cracks in clayey soils, the 


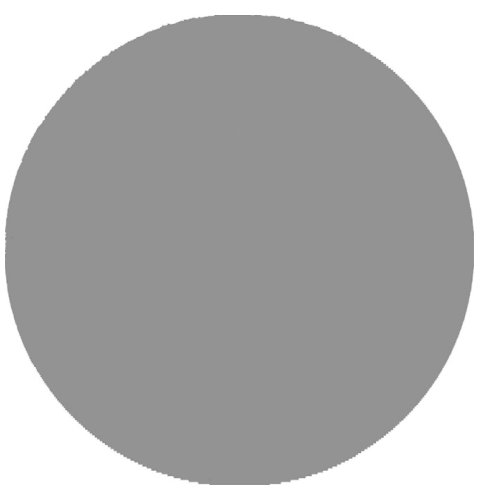

(a)

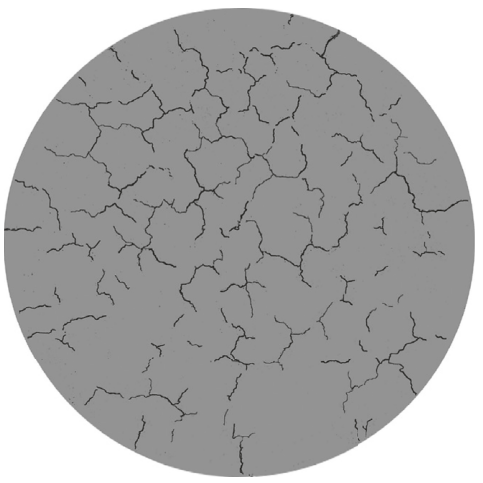

(d)

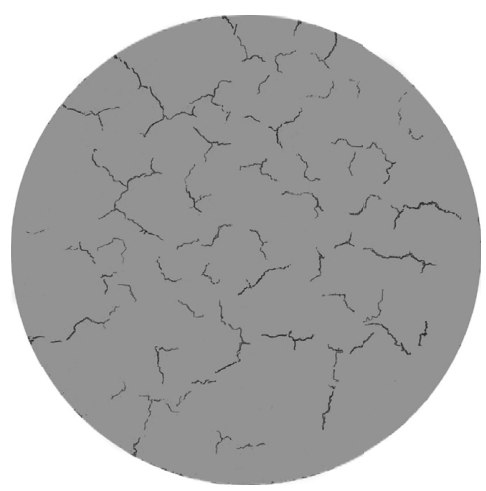

(b)

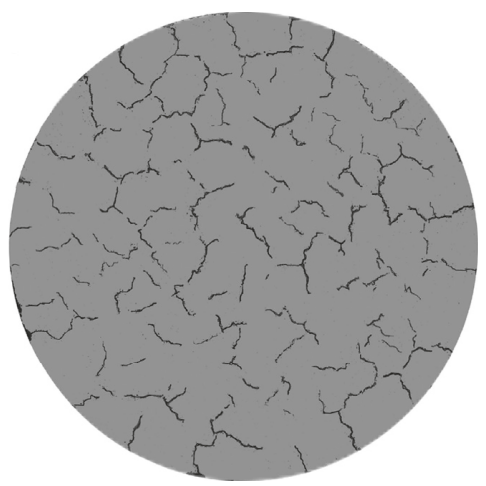

(e)

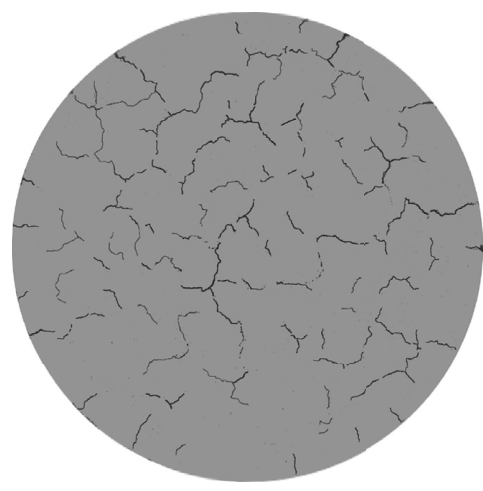

(c)

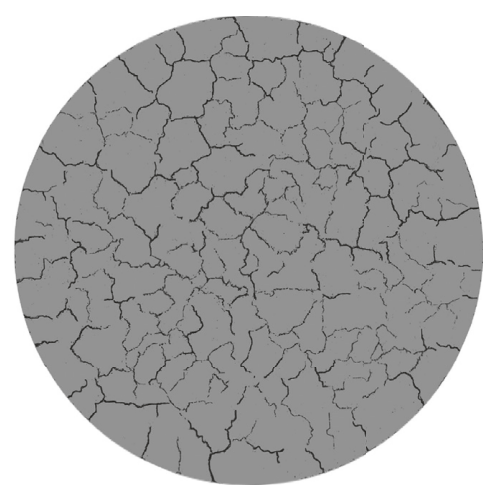

(f)

Figure 6: Grayscale images of the cracks on the sample surface after different wetting and drying cycles. (a) Original sample. (b) Cycle one. (c) Cycle two. (d) Cycle three. (e) Cycle four. (f) Cycle eight.

drying cracks in completely disintegrated carbonaceous mudstone are relatively narrow due to the low proportion of clay minerals and the large dry density (or degree of compaction) of the sample. In addition, the cracks in completely disintegrated carbonaceous mudstone show more or less zigzag features and the shape of the produced polygon grids is quite irregular, which are different from the crack patterns formed in clayey soils. This is probably because of the existence of large grains (i.e., fine sand) in completely disintegrated carbonaceous mudstone.

The micrographs of the surface of the sample after different wetting and drying cycles were obtained by means of scanning electron microscopy, and they are illustrated in Figure 7. It is observed that, in the initial state, the particles on the sample surface are tightly bound, but some primary small pores of several microns also present. Under cyclic wetting and drying, the sample swells and shrinks, causing a loose structure of the sample and many cracks of different sizes and shapes. After the first wetting and drying cycle, the sample surface is smoother than that in the initial state, but a few fine cracks appear. After the fourth wetting and drying cycle, the pores on the sample surface increase in size and number and show a tendency of interconnection. The area with numerous large pores is usually a weak zone of the sample. Water can enter the pores after wetting and evaporate after drying. The swelling and shrinkage of the soil inevitably cause damage to the soil structure. Therefore, the pores are connected and penetrated, and the cracks are generated.
4.2. Evolution Characteristics of Crack Parameters. Based on the image processing technique, the evolution process of the cracks on the surface of the completely disintegrated carbonaceous mudstone sample after different wetting and drying cycles was quantitatively analyzed. The quantitative parameters corresponding to different wetting and drying cycles are given in Table 2. According to the data in Table 2, the relationship between each crack parameter and the number of wetting and drying cycles can be obtained.

The variations of $l_{\max }$ and $d_{\max }$ of cracks after different wetting and drying cycles are shown in Figure 8. It is noted that both $l_{\max }$ and $d_{\max }$ values increase with the increase in the number of wetting and drying cycles. The increases of $l_{\max }$ and $d_{\max }$ during the third wetting and drying cycle are the largest, and the changes of them after this cycle are relatively stable. In the process of eight wetting and drying cycles, the maximum values of $l_{\max }$ and $d_{\max }$ are $40.87 \mathrm{~mm}$ and $2.3 \mathrm{~mm}$, respectively.

The variations of $N$ and $A$ of cracks with wetting and drying cycles are illustrated in Figure 9. It is observed that $N$ increases with the increase in the number of wetting and drying cycles. The $N$ value reaches the maximum after seven wetting and drying cycles and then declines after the peak. $A$ grows slowly during the first two wetting and drying cycles. After that, $A$ gradually increases and finally stabilizes as the number of wetting and drying cycles increases. The reason for $N$ increases first and then decreases is that the cracks in the soil do not develop immoderately under cyclic wetting 

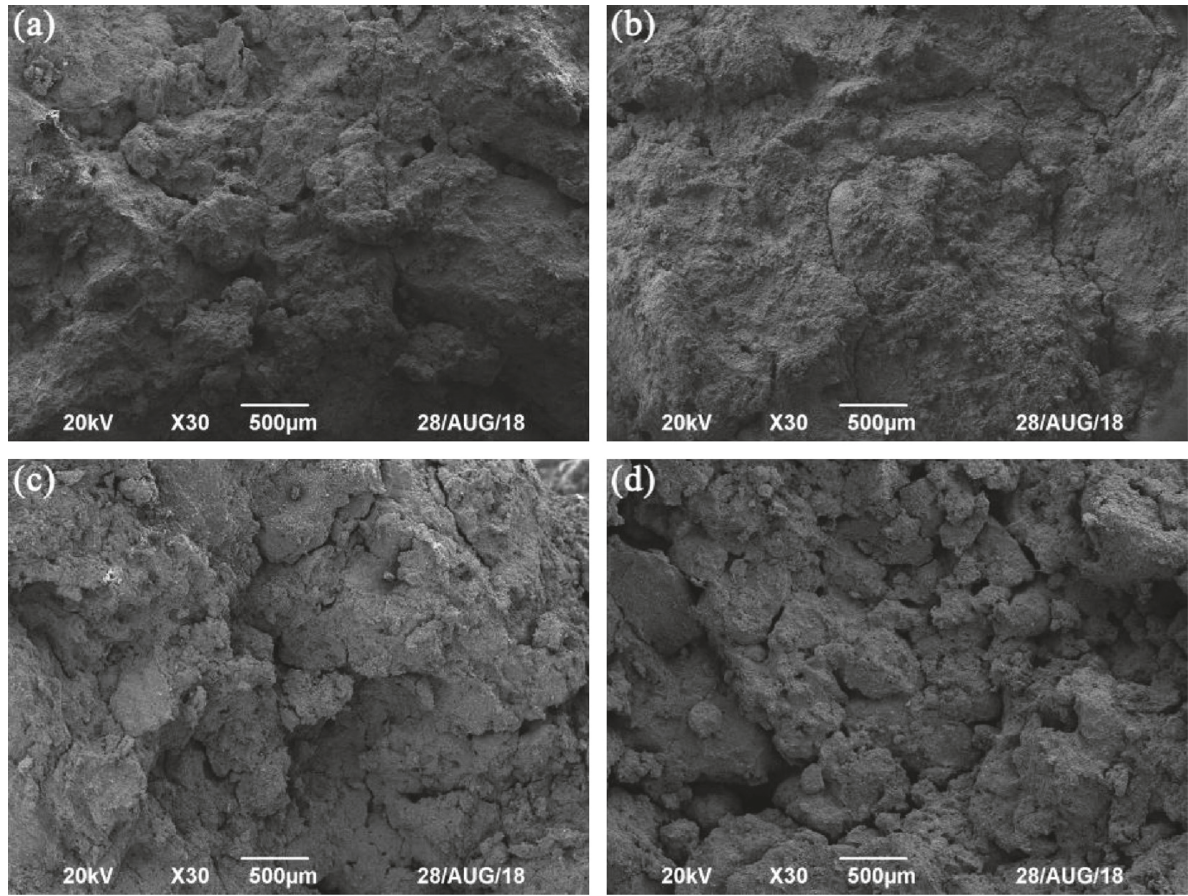

Figure 7: Scanning electron microscopy images of the sample surface after different wetting and drying cycles. (a) Original sample. (b) Cycle one. (c) Cycle four. (d) Cycle eight.

TABLE 2: Crack parameters of the completely disintegrated carbonaceous mudstone.

\begin{tabular}{lccccc}
\hline Cycle number & $l_{\max }(\mathrm{mm})$ & $d_{\max }(\mathrm{mm})$ & $A\left(\mathrm{~mm}^{2}\right)$ & $N$ & $\rho_{\mathrm{s}}\left(\mathrm{m}^{-1}\right)$ \\
\hline 1 & 24.67 & 0.99 & 25.48 & 48 & 0.17 \\
2 & 25.33 & 1.04 & 31.56 & 53 & 0.17 \\
3 & 33.48 & 1.61 & 55.82 & 58 & 0.27 \\
4 & 36.02 & 1.65 & 71.70 & 61 & 0.36 \\
5 & 38.82 & 1.94 & 93.75 & 74 & 0.39 \\
6 & 38.95 & 2.05 & 128.30 & 100 & 0.39 \\
7 & 39.09 & 2.14 & 136.60 & 104 & 0.45 \\
8 & 40.87 & 2.30 & 139.78 & 86 & 0.45 \\
\end{tabular}

and drying. When there are massive cracks, several adjacent cracks intersect each other to from a single crack, which causes the decrease in $N$. After the intersection of cracks, a large number of small grids are formed on the sample surface, and thus $A$ further increases.

The length and width (i.e., $l_{\max }$ and $d_{\max }$ ) can represent some aspects of the crack characteristics, whereas they cannot characterize the overall development of the cracks on the sample surface. For this reason, the values of $\rho_{\mathrm{s}}$ and $\delta_{\mathrm{f}}$ were analyzed, and their variations with the number of wetting and drying cycles are presented in Figure 10. It is observed that the development of the cracks in the completely disintegration carbonaceous mudstone sample can be divided into three stages, i.e., the slow development, the rapid development, and the stable development, which is consistent with the field test results of ground cracking reported by Li and Zhang [20]. The $\rho_{\mathrm{s}}$ and $\delta_{\mathrm{f}}$ values first increase with the increasing number of wetting and drying cycles and then tend to be stable. The values of $\rho_{\mathrm{s}}$ and $\delta_{\mathrm{f}}$ do not change much during the first and second wetting and drying cycles, increase rapidly beginning from the third wetting, and drying cycle and are gradually stabilized after the sixth wetting and drying cycle.
To explore the evolution of the directions of the cracks in the completely disintegrated carbonaceous mudstone subjected to cyclic wetting and drying, a simple rose diagram was introduced to describe the crack directions. The azimuth of the rose diagram represents the direction of the cracks, and the radius of the rose diagram represents the crack number in a certain direction. The rose diagram of the cracks after different wetting and drying cycles is shown in Figure 11. It is observed that the new cracks are mainly generated on the basis of the existing cracks, and some cracks disappear under wetting. The cracks are mainly developed towards the directions of $0^{\circ}-90^{\circ}$ and $300^{\circ}-360^{\circ}$, after the first five wetting and drying cycles, and then the crack development in the directions of $30^{\circ}, 90^{\circ}, 140^{\circ}-150^{\circ}$, and $180^{\circ}-270^{\circ}$ is more significant than that in other directions. After the first wetting and drying cycle, the rose diagram of the cracks is symmetrical about the line passing through $150^{\circ}$ and $330^{\circ}$, exhibiting a butterfly shape. From the third to the fifth wetting and drying cycles, the area of the upper part of the rose diagram is larger than that of the lower part. This indicates that the number of the cracks with the directions of $270^{\circ}-360^{\circ}$ and $0^{\circ}-90^{\circ}$ increases rapidly from the third to fifth 


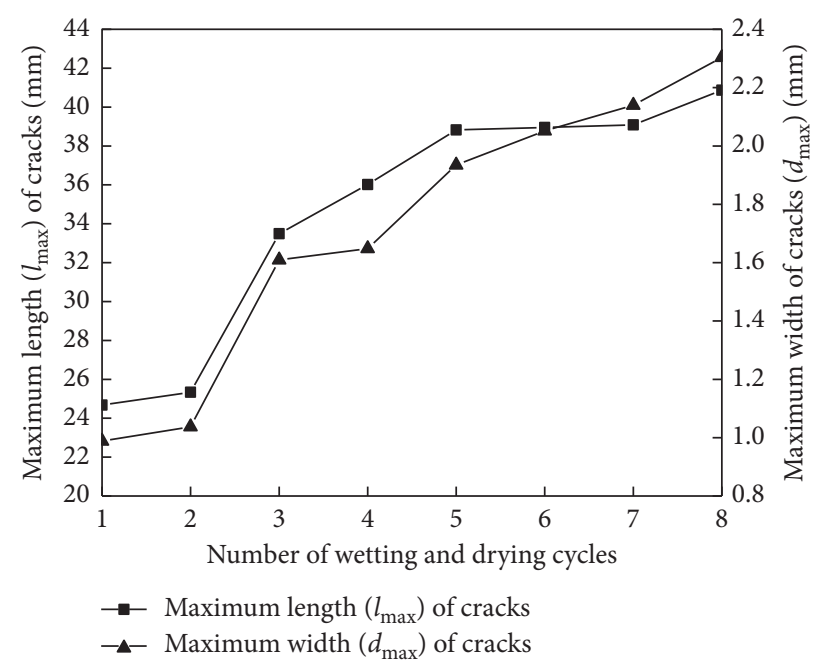

Figure 8: Curves of maximum length and maximum width of cracks.

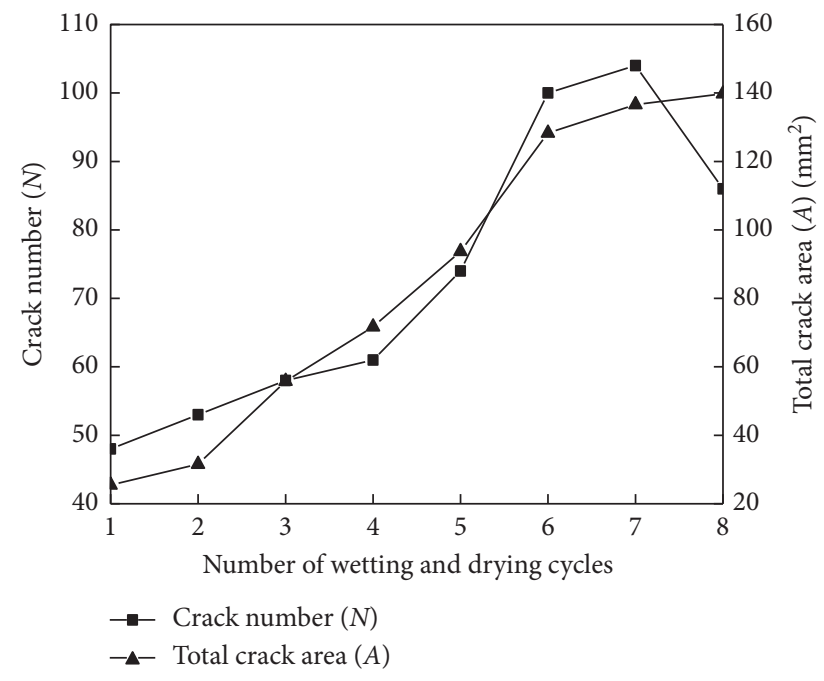

FIgURE 9: Curves of the crack number and total crack area.

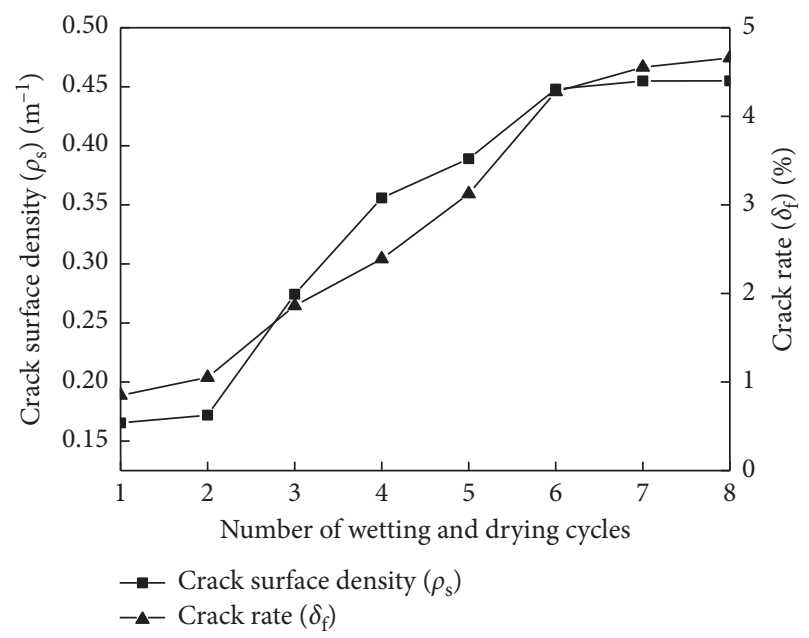

Figure 10: Curves of crack surface density and crack rate.
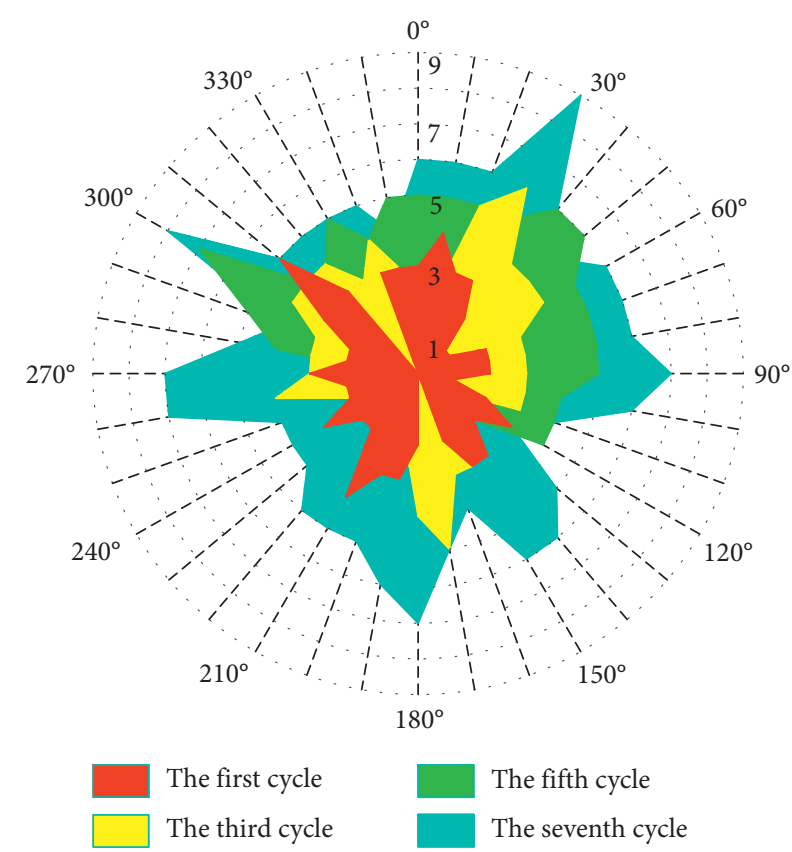

FIgURE 11: Rose diagram of crack development.

wetting and drying cycles. Moreover, the cracks have a wider range of direction after the seventh wetting and drying cycle than those after the fifth wetting and drying cycle. From the fifth to the seventh wetting and drying cycles, the development rate of crack in the directions of $40^{\circ}-60^{\circ}, 110^{\circ}-130^{\circ}$, $280^{\circ}-290^{\circ}$. and $310^{\circ}-360^{\circ}$ is small and that in other directions is large.

The reasons for the difference of development rate and distribution of cracks during cyclic wetting and drying are as follows. The cracks with small widths heal in the wetting process. In addition, the cracks with large widths in the drying process have a large water loss space, which causes a greater nonuniform stress between the surface and interior of the sample. Finally, the existing cracks continue to develop and create new cracks.

4.3. Evolution Mechanism of Cracks under Cyclic Wetting and Drying. The soil sample is likely to shrink during drying owing to the generation of suction. If the drying shrinkage is constrained, cracks occur when the produced tensile stress exceeds the tensile strength of soil [32-34]. In this study, the shrinkage constraints mainly come from the frictional bottom boundary and soil inhomogeneity (e.g., large grains and pores).

As presented previously, the surface density of crack increases with increasing number of wetting and drying cycles. This is because with the increase of wetting and drying cycles, the soil tends to relax and produces irreversible plastic deformation. New cracks develop on the basis of the existing cracks, but the sample area is assumed to be constant during cyclic wetting and drying, leading to the increase in the surface density of crack. The carbonaceous mudstone has the characteristics of swelling and shrinkage, a part of cracks heal in the wetting process, and the existing cracks open again in the drying process. The free surface 
formed after the soil cracking changes the gradient distribution of the water content of the sample. The new water content gradient leads the tensile stress of soil to be greater than the tensile strength of soil, and thus new cracks appear. As the number of wetting and drying cycles increases, the maximum length of crack increases, and the phenomenon of the intersection of cracks occur. As a result, the number of cracks decreases, but the crack intersection does not affect the total area of cracks.

From the rose diagram of crack development, it is noted that, in the early stage, the cracks develop mainly towards the direction of $0^{\circ}-90^{\circ}$ and $300^{\circ}-360^{\circ}$. The development of cracks destroys the soil integrity and causes the expansion of the distribution area of cracks. Particularly, the development of cracks in the directions of $30^{\circ}, 90^{\circ}, 140^{\circ}-150^{\circ}$, and $180^{\circ}-270^{\circ}$ is significantly faster than that in other directions.

\section{Conclusions}

In this experimental study, the evolution characteristics of the cracks in the completely disintegrated carbonaceous mudstone sample after different wetting and drying cycles were investigated. The following conclusions can be drawn:

(1) With the increase in the number of wetting and drying cycles, the number of the cracks on the surface of the completely disintegrated carbonaceous mudstone sample gradually increases. After the fourth wetting and drying cycle, the primary and secondary cracks of the sample intersect with each other and gradually form irregular polygonal grids.

(2) The development of the cracks on the surface of the completely disintegrated carbonaceous mudstone sample can be divided into three stages, i.e., slow development, rapid development, and stable development. The surface density of crack and crack rate first increase and then tend to be stable as the number of wetting and drying cycles increases.

(3) New cracks are mainly developed on the basis of the existing cracks under cyclic wetting and drying, and some existing cracks disappear in the wetting process.

(4) The cracks mainly occur in the directions of $0^{\circ}-90^{\circ}$ and $300^{\circ}-0^{\circ}$ after the first five wetting and drying cycles, and then the crack development in the directions of $30^{\circ}, 90^{\circ}, 140^{\circ}-150^{\circ}$, and $180^{\circ}-270^{\circ}$ is more significant than that in other directions.

\section{Data Availability}

The data used to support the findings of this study are available from the corresponding author upon request.

\section{Conflicts of Interest}

The authors declare that there are no conflicts of interest regarding the publication of this paper.

\section{Acknowledgments}

This work was supported by the National Key Research and Development Program of China (2017YFC0805307), the National Natural Science Foundation of China (51838001, 51878070, 51878078, and 51678074), the Excellent Youth Foundation of Natural Science Foundation of Hunan Province (2018JJ1026), the Key Project of Education Department of Hunan Province (17A008), the Postgraduate Research and Innovation Project of Hunan Province (CX2018B528), and the Open Fund of Engineering Research Center of Catastrophic Prophylaxis and Treatment of Road and Traffic Safety of Ministry of Education (Changsha University of Science \& Technology) (kfj170404).

\section{References}

[1] L. Zeng, X. Lou, J. Zhang, C. Wu, J. Liu, and C. Jia, "Carbonaceous mudstone and lignin-derived activated carbon and its application for supercapacitor electrode," Surface and Coatings Technology, vol. 357, pp. 580-586, 2019.

[2] Y. Li, Y.-F. Chen, G.-J. Zhang, Y. Liu, and C.-B. Zhou, "A numerical procedure for modeling the seepage field of watersealed underground oil and gas storage caverns," Tunnelling and Underground Space Technology, vol. 66, pp. 56-63, 2017.

[3] L. Zeng, J. Ye, J. Zhang, J. Liu, and C. Jia, "A promising SPEEK/MCM composite membrane for highly efficient vanadium redox flow battery," Surface and Coatings Technology, vol. 358, pp. 167-172, 2019.

[4] O. Rincon, A. Shakoor, and M. Ocampo, "Investigating the reliability of $\mathrm{H} / \mathrm{V}$ spectral ratio and image entropy for quantifying the degree of disintegration of weak rocks," Engineering Geology, vol. 207, pp. 115-128, 2016.

[5] J. H. Li and L. M. Zhang, "Geometric parameters and REV of a crack network in soil," Computers and Geotechnics, vol. 37, no. 4, pp. 466-475, 2010.

[6] P. H. Morris, J. Graham, and D. J. Williams, "Cracking in drying soils," Canadian Geotechnical Journal, vol. 29, no. 2, pp. 263-277, 1992.

[7] M.-A. Brideau, A. Pedrazzini, D. Stead, C. Froese, M. Jaboyedoff, and D. van Zeyl, "Three-dimensional slope stability analysis of South Peak, Crowsnest Pass, Alberta, Canada," Landslides, vol. 8, no. 2, pp. 139-158, 2011.

[8] L. Zeng, H.-b. Bian, Z.-n. Shi, and Z.-m. He, "Forming condition of transient saturated zone and its distribution in residual slope under rainfall conditions," Journal of Central South University, vol. 24, no. 8, pp. 1866-1880, 2017.

[9] H. Dong, R. Huang, and Q.-F. Gao, "Rainfall infiltration performance and its relation to mesoscopic structural properties of a gravelly soil slope," Engineering Geology, vol. 230, pp. 1-10, 2017.

[10] A. N. Abu-Hejleh and D. Znidarčić, "Desiccation theory for soft cohesive soils," Journal of Geotechnical Engineering, vol. 121, no. 6, pp. 493-502, 1995.

[11] H. Peron, T. Hueckel, L. Laloui, and L. B. Hu, "Fundamentals of desiccation cracking of fine-grained soils: experimental characterisation and mechanisms identification," Canadian Geotechnical Journal, vol. 46, no. 10, pp. 1177-1201, 2009.

[12] L. Zeng, J. Liu, J.-h. Zhang, H.-b. Bian, and W.-h. Lu, "Effect of colluvial soil slope fracture's anisotropy characteristics on rainwater infiltration process," Advances in Civil Engineering, vol. 2018, Article ID 7351628, 11 pages, 2018. 
[13] J. Zhang, J. Peng, J. Zheng, and Y. Yao, "Characterisation of stress and moisture-dependent resilient behaviour for compacted clays in South China," Road Materials and Pavement Design, vol. 20, pp. 1-14, 2018.

[14] J. Zhang, J. Peng, J. Zheng, L. Dai, and Y. Yao, "Prediction of resilient modulus of compacted cohesive soils in South China," International Journal of Geomechanics, vol. 19, no. 7, article 04019068, 2019.

[15] C.-S. Tang, Y.-J. Cui, A.-M. Tang, and B. Shi, "Experiment evidence on the temperature dependence of desiccation cracking behavior of clayey soils," Engineering Geology, vol. 114, no. 3-4, pp. 261-266, 2010.

[16] Y. J. Cui, C. S. Tang, A. M. Tang et al., "Investigation of soil desiccation cracking using an environmental chamber," Rivista Italiana di Geotecnica, vol. 24, pp. 9-20, 2014.

[17] M. R. Lakshmikantha, P. C. Prat, and A. Ledesma, "Experimental evidence of size effect in soil cracking," Canadian Geotechnical Journal, vol. 49, no. 3, pp. 264-284, 2012.

[18] R. N. Tollenaar, L. A. van Paassen, and C. Jommi, "Observations on the desiccation and cracking of clay layers," Engineering Geology, vol. 230, pp. 23-31, 2017.

[19] K. A. Shorlin, J. R. de Bruyn, M. Graham, and S. W. Morris, "Development and geometry of isotropic and directional shrinkage-crack patterns," Physical Review E, vol. 61, no. 6, pp. 6950-6957, 2000.

[20] J. H. Li and L. M. Zhang, "Study of desiccation crack initiation and development at ground surface," Engineering Geology, vol. 123, no. 4, pp. 347-358, 2011.

[21] C.-S. Tang, D.-Y. Wang, C. Zhu, Q.-Y. Zhou, S.-K. Xu, and B. Shi, "Characterizing drying-induced clayey soil desiccation cracking process using electrical resistivity method," Applied Clay Science, vol. 152, pp. 101-112, 2018.

[22] Y. Wang, C. H. Li, and Y. Z. Hu, "X-ray computed tomography (CT) observations of crack damage evolution in soilrock mixture during uniaxial deformation," Arabian Journal of Geosciences, vol. 11, no. 9, 2018.

[23] Q.-F. Gao, M. Jrad, L. I. Ameu, M. Hattab, and J.-M. Fleureau, "Dilatancy phenomenon study in remolded clays-a micromacro investigation," Springer Series in Geomechanics and Geoengineering, vol. 1, pp. 148-152, 2018.

[24] J. Li, J. Zhang, G. Qian, J. Zheng, and Y. Zhang, "Threedimensional simulation of aggregate and asphalt mixture using parameterized shape and size gradation," Journal of Materials in Civil Engineering, vol. 31, no. 3, article 04019004, 2019.

[25] Q.-F. Gao, H. Dong, R. Huang, and Z.-F. Li, "Structural characteristics and hydraulic conductivity of an eluvialcolluvial gravelly soil," Bulletin of Engineering Geology and the Environment, vol. 79, 2019.

[26] ASTM D2487-17, Standard Practice for Classification of Soils for Engineering Purposes (Unified Soil Classification System), ASTM International, West Conshohocken, PA, USA, 2017.

[27] D. A. Sun, G. You, Z. Annan, and S. Daichao, "Soil-water retention curves and microstructures of undisturbed and compacted Guilin lateritic clay," Bulletin of Engineering Geology and the Environment, vol. 75, no. 2, pp. 781-791, 2016.

[28] C. Zhang, Z.-y. Cai, Y. h. Huang, and H. Chen, "Laboratory and centrifuge model tests on influence of swelling rock with drying-wetting cycles on stability of canal slope," Advances in Civil Engineering, vol. 2018, Article ID 4785960, 10 pages, 2018.

[29] Y. Zhang, W. M. Ye, B. Chen, Y. G. Chen, and B. Ye, "Desiccation of NaCl-contaminated soil of earthen heritages in The Site of Yar City, Northwest China," Applied Clay Science, vol. 124-125, pp. 1-10, 2016.

[30] C. Tang, B. Shi, C. Liu, L. Zhao, and B. Wang, "Influencing factors of geometrical structure of surface shrinkage cracks in clayey soils," Engineering Geology, vol. 101, no. 3-4, pp. 204217, 2008.

[31] N. Yesiller, C. J. Miller, G. Inci, and K. Yaldo, "Desiccation and cracking behavior of three compacted landfill liner soils," Engineering Geology, vol. 57, no. 1-2, pp. 105-121, 2000.

[32] H. Peron, L. Laloui, T. Hueckel, and L. B. Hu, "Desiccation cracking of soils," Revue Européenne de Génie Civil, vol. 13, no. 7-8, pp. 869-888, 2009.

[33] C.-S. Tang, B. Shi, C. Liu, L. Gao, and H. I. Inyang, "Experimental investigation of the desiccation cracking behavior of soil layers during drying," Journal of Materials in Civil Engineering, vol. 23, no. 6, pp. 873-878, 2011.

[34] N. I. Thusyanthan, W. A. Take, S. P. G. Madabhushi, and M. D. Bolton, "Crack initiation in clay observed in beam bending," Géotechnique, vol. 57, no. 7, pp. 581-594, 2007. 


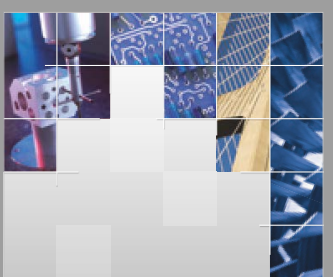

\section{Enfincering}
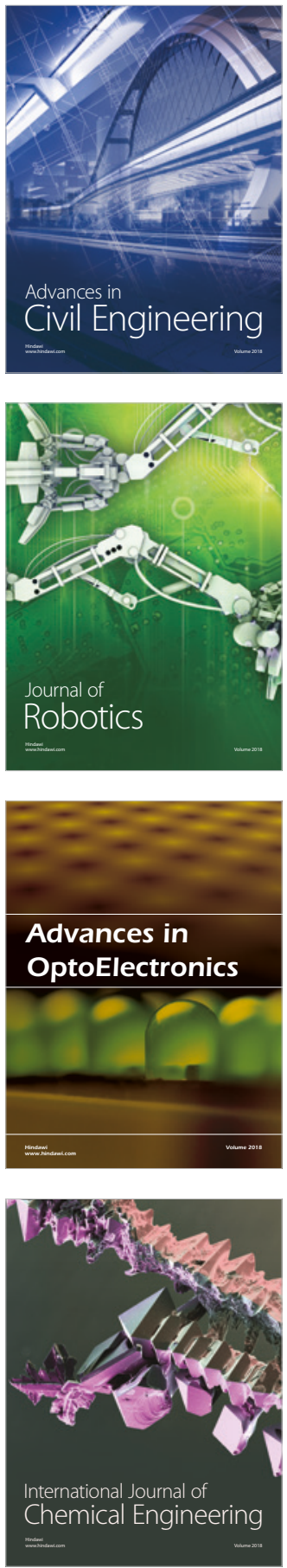

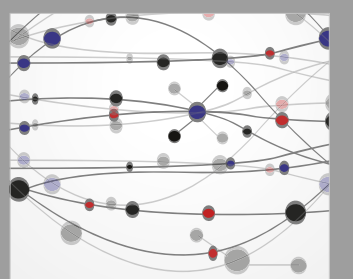

\section{Rotating \\ Machinery}

The Scientific World Journal

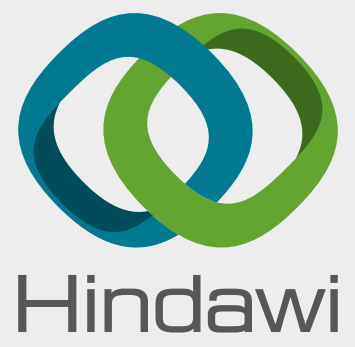

Submit your manuscripts at

www.hindawi.com
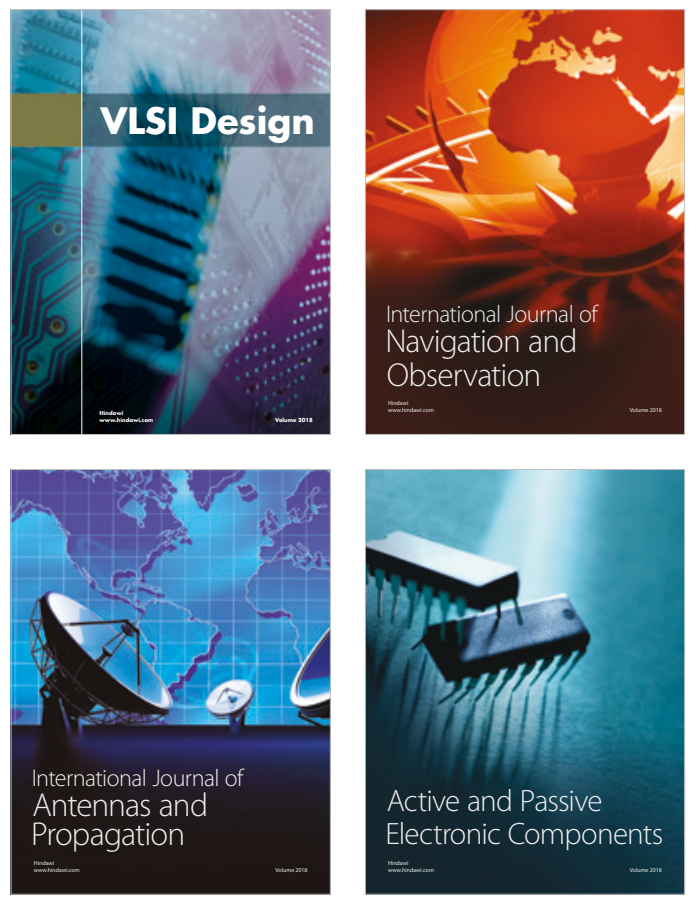
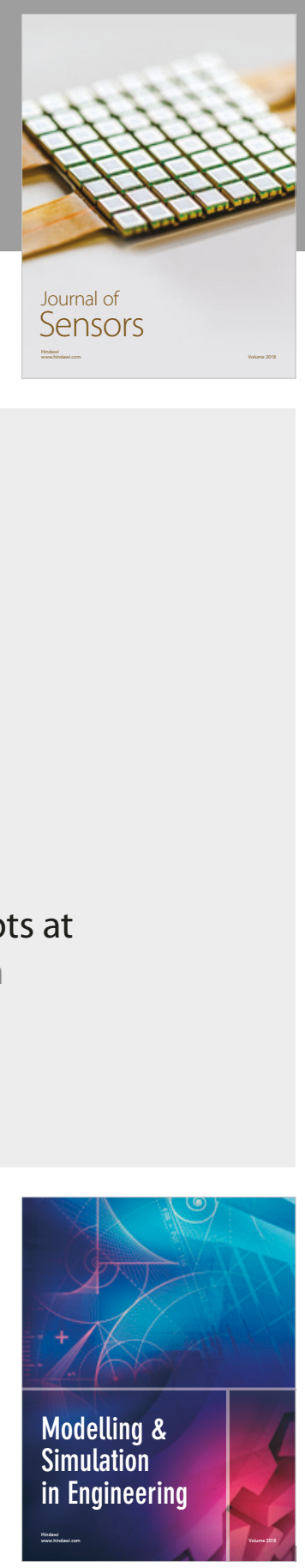

\section{Advances \\ Multimedia}
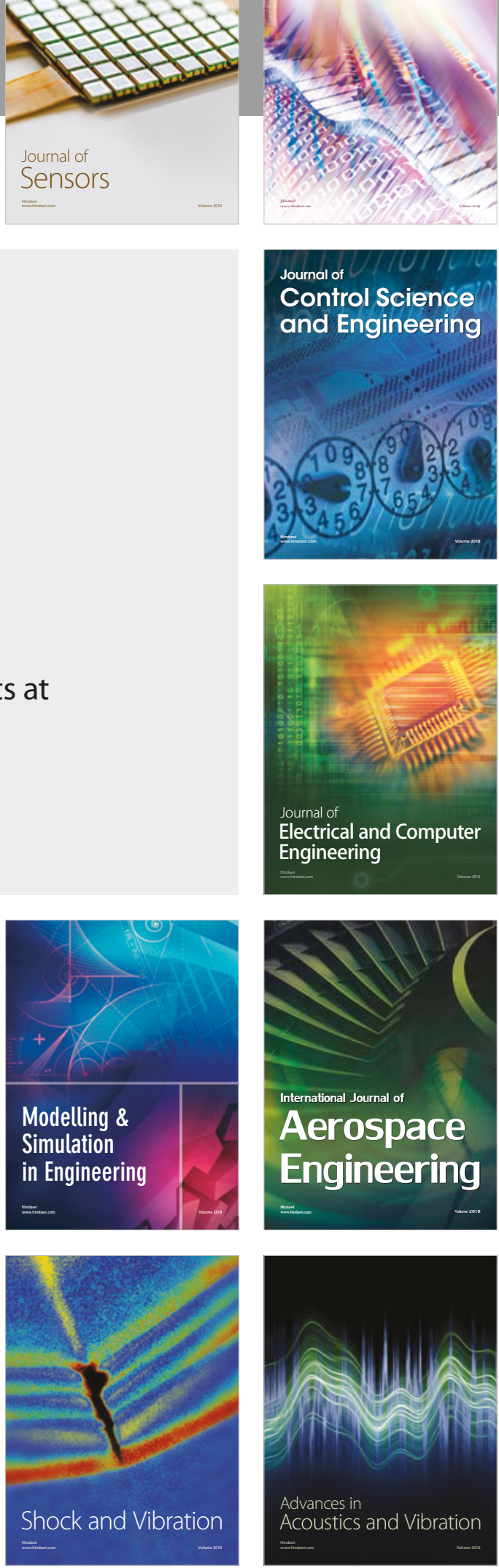